\title{
Conceptual design of planetary gearbox system for constant generator speed in hydro power plant
}

\author{
Bhargav $^{1}$, M. A. Parameshwaran ${ }^{2}$, Sivaraj S. ${ }^{2}$ and Nithin Venkataram ${ }^{1 *}$, \\ ${ }^{1}$ Dept. of Mechanical and Manufacturing Engineering, Ramaiah University of Applied Sciences \\ Bangalore, India \\ ${ }^{2}$ MAGTORQ Pvt. Ltd., Hosur, Tamil Nadu, India
}

\begin{abstract}
Micro Hydro Power Plant (MHPP) is emerging as one of the most clean, renewable and reliable energy technology for harnessing power. In MHPP hydro governors are avoided, that results in turbine speed fluctuation. MHPP requires either speed or torque amplification of generator for constant power generation. To achieve this, planetary gear transmission system is explored for MHPP due to its higher efficiency and compact size. A conceptual planetary gearbox system is developed for MHPP to maintain constant generator speed. The conceptual gearbox is designed, modelled and analysed using ADAMS software. Simulation results are found to be in close agreement with analytical results. Hence, conceptual design of planetary gearbox can be used to govern constant generator speed. In this paper, a MHPP which generate constant power of 5 $\mathrm{kW}$ at constant generator speed of $1490 \mathrm{rpm}$ is analysed and validated
\end{abstract}

\section{Introduction}

Electric energy is an essential requirement and its availability plays an important role in day to day life. The gap between the demand and supply of electricity is increasing rapidly and it is not possible to meet the demand, because of which most of the rural areas is still starved by the grid supply. Hence there is a great need to produce power for remote rural areas. Micro Hydro Power Plant (MHPP) is one of the emerging solutions for rural electrification, since it is built near valley, small rivers which are located far away from the national grid [1]. The power generating capacity of MHPP ranges between $5 \mathrm{~kW}$ to $100 \mathrm{~kW}$ [2]. In MHPP, the powerhouse is directly placed on the runway stream with minimal arrangement for directing water towards powerhouse and hence hydro governor can be avoided. Thus MHPP needs no reservoir for power generation. The water from the runway stream is used for power generation and goes back to runway stream through tailrace. Thus MHPP has a minimal impact on local ecosystem when compared to large hydro power plant [3]. Power house of MHPP expects minimum maintenance, since it is located far from the national grid. In addition, the power house needs a good control system for maintaining constant power generation. A good control system will have a uniform transmission, which

* Corresponding author: nithin31@gmail.com 
results in constant turbine and generator speed. In the absence of hydro governor, the uneven flow of water will lead to variable turbine speed, which results in variable generator speed. Thus implementation of MHPP is a challenging task due to lack of technical development for maintaining constant generator speed. Hence a new design of transmission system is required to govern constant generator speed for variable input turbine speed [4].

The speed control in power production is possible through a transmission system. In MHPP, two types of transmission can be used, direct transmission and indirect transmission. In direct transmission turbine shaft is directly coupled to generator shaft, which yields in very high efficiency. However, both turbine and generator needs to be designed as per the requirement which is uneconomic. Hence it is not suitable for MHPP. To match both turbine speed and generator speed, indirect transmission system is used. In MHPP, the turbine speed ranges between 100-500 rpm and standard generator runs at much higher rotation per minute, so a speed multiplier is used. From literature, it is observed that there are various indirect transmission systems such as chain, belt and gear drive available for MHPP. Chain and belt drive has low efficiency and load sharing capacity, hence it is used in low very transmission ratio application for power generating capacity under $3 \mathrm{~kW}$ [5].

In addition to this, the gear transmissions are used in power transmission system. Table 1 shows the comparison between gear and planetary transmission. The planetary gear drive has high power to weight ratio with high load carrying capacity [6]. Also, more than one speed ratio is achieved when compare to fixed axis gearbox. Planetary gearbox has good efficiency, reliability and compactness hence it is preferred for MHPP [7].

Table 1. Comparison between gear drive planetary gear drive

\begin{tabular}{|l|l|l|l|}
\hline $\begin{array}{c}\text { Type of } \\
\text { transmission } \\
\text { system }\end{array}$ & Efficiency & Application & \multicolumn{1}{c|}{ Features } \\
\hline $\begin{array}{l}\text { Gear } \\
\text { transmission }\end{array}$ & $75-85 \%$. & Low transmission & $\begin{array}{l}\text { Higher transmission ratio, no of } \\
\text { stages increases, increasing overall } \\
\text { dimensions }\end{array}$ \\
\hline $\begin{array}{l}\text { Planetary gear } \\
\text { transmission }\end{array}$ & $95 \%$ & High transmission & $\begin{array}{l}\text { Compact and high load sharing } \\
\text { capacity }\end{array}$ \\
\hline
\end{tabular}

In MHPP, generator operates at higher speed than the turbine. Fig. 1 shows conventional planetary drive transmission. Conventional planetary gear drive either amplifies or reduces speed depending upon the input conditions. When ring gear is fixed, input is given to turbine coupled to carrier and output is extracted from sun gear coupled to generator, planetary gear transmission acts as speed multiplier. Similarly, if the input motion is given to sun gear and output is extracted from carrier, planetary gear transmission act as speed reducer. If the input speed varies, so does the output speed by a factor of transmission ratio. There is no control over variable turbine speed for maintaining constant output speed i.e. if turbine speed varies the generator speed will also vary. Hence there is a need to develop a novel concept to maintain constant generator speed. 


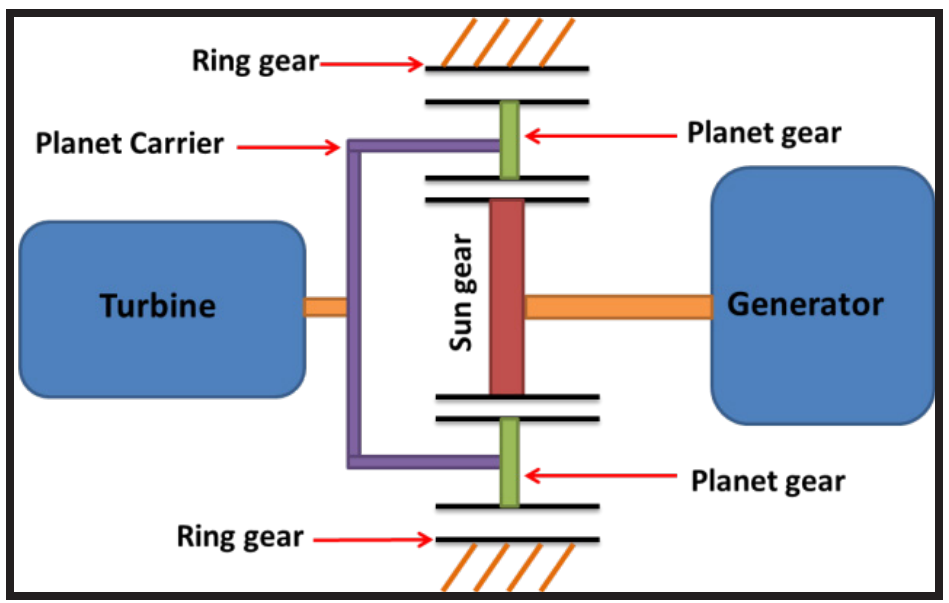

Fig. 1. Existing concept used in planetary gear drive for MHPP

\section{Conceptual design}

A conceptual design is developed to maintain constant generator speed. The design consists of planetary gearbox in which ring gear is fixed, input is given to turbine coupled carrier and output is extracted from sun gear coupled to generator, the input speed amplifies depending on transmission ratio. On the other hand, if the ring gear is allowed to rotate in the direction of the planet gear, the output speed equals to sum of amplified speed due to carrier and amplified speed due to ring gear. The generalized relation between sun, carrier and ring gear speed is provided in eqn. 1 .

$$
N_{\text {sun }}=N_{\text {sun-carrier }}+N_{\text {sun-ring gear }}
$$

When the ring gear rotates in the direction opposite to the planet gear, the ring gear motion opposes the planet gear motion resulting in reduced output. In other words output speed equals difference in speed due to carrier and speed due to ring gear. The generalized relation is provided in eqn. 2 .

$$
N_{\text {sun }}=N_{\text {sun-carrier }}-N_{\text {sun-ring gear }}
$$

From the eqn. 1 and 2, it is observed that the constant speed can be achieved by controlling the speed of ring gear. Based on this understanding, a concept is designed for maintaining constant generator speed. The conceptual design consists of single stage planetary gearbox, with auxiliary motor as shown in Fig. 2. The planetary gearbox consists of sun gear, planet carrier and ring gear. The ring gear is connected to auxiliary unit. The auxiliary unit consists of a reduction helical and spur gearbox, which is coupled to an auxiliary motor.

Planetary gearbox system is coupled between turbine and generator. Turbine shaft is connected to the planet carrier, which acts as input to the planetary gearbox. Output of planetary gear is extracted from sun gear which is connected to generator. 


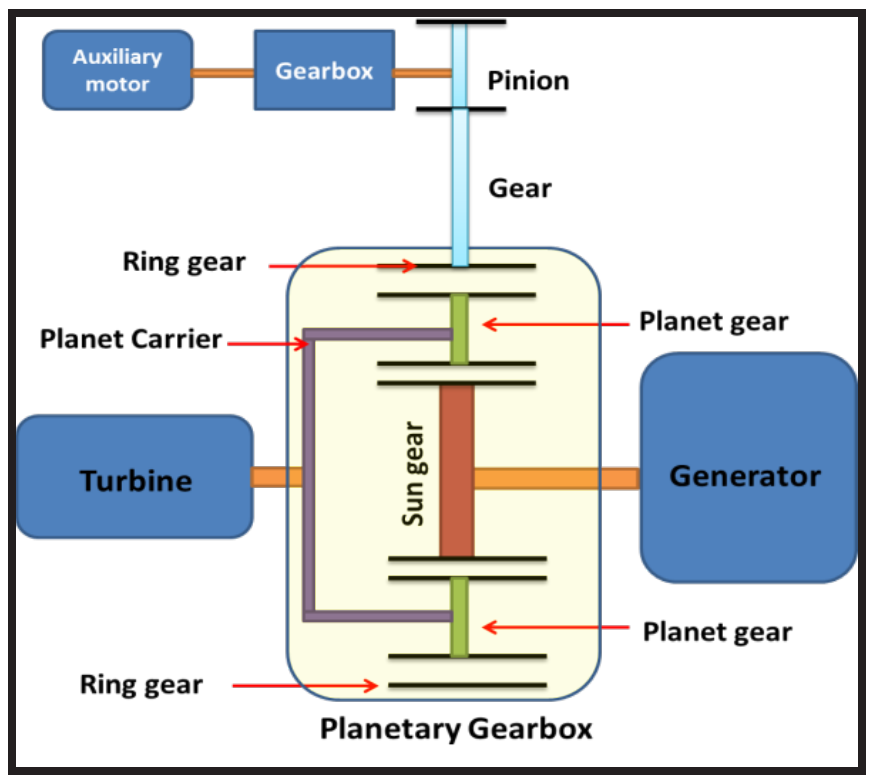

Fig. 2. Line diagram of planetary gearbox system to govern constant generator speed

\section{Analytical calculations}

\subsection{Design requirement}

The developed conceptual design of planetary gearbox system is an indirection transmission system. The planetary gearbox is designed for transmitting turbine speed to generator. It is assumed that turbine rotates at a speed of $150 \mathrm{rpm}$ and standard generator for generating $5 \mathrm{~kW}, 50 \mathrm{~Hz}$ rotates at $1500 \mathrm{rpm}$. Hence single stage planetary gearbox with 3 planet gear is design for 1:9.9 speed ratio.

\subsection{Design of planetary gearbox}

Table 2. Tabulation method for arriving at no. of teeth's in gear (Maitra, 2001)

\begin{tabular}{|l|l|l|l|}
\hline \multicolumn{1}{|c|}{ Planet Carrier } & \multicolumn{1}{|c|}{ Sun Gear } & \multicolumn{1}{c|}{ Planet Gear } & \multicolumn{1}{c|}{ Ring Gear } \\
\hline 0 & +1 & $(\mathrm{Zs} / \mathrm{Zp})$ & $-(\mathrm{Zs} / \mathrm{Zi})$ \\
\hline 0 & $\mathrm{x}$ & $-(\mathrm{Zs} / \mathrm{Zp})^{*} \mathrm{x}$ & $-(\mathrm{Zs} / \mathrm{Zi})^{*} \mathrm{x}$ \\
\hline $\mathrm{y}$ & $\mathrm{x}+\mathrm{y}$ & $\mathrm{y}-(\mathrm{Zs} / \mathrm{Zp})^{*} \mathrm{x}$ & $\mathrm{y}-(\mathrm{Zs} / \mathrm{Zi})^{*} \mathrm{x}$ \\
\hline
\end{tabular}




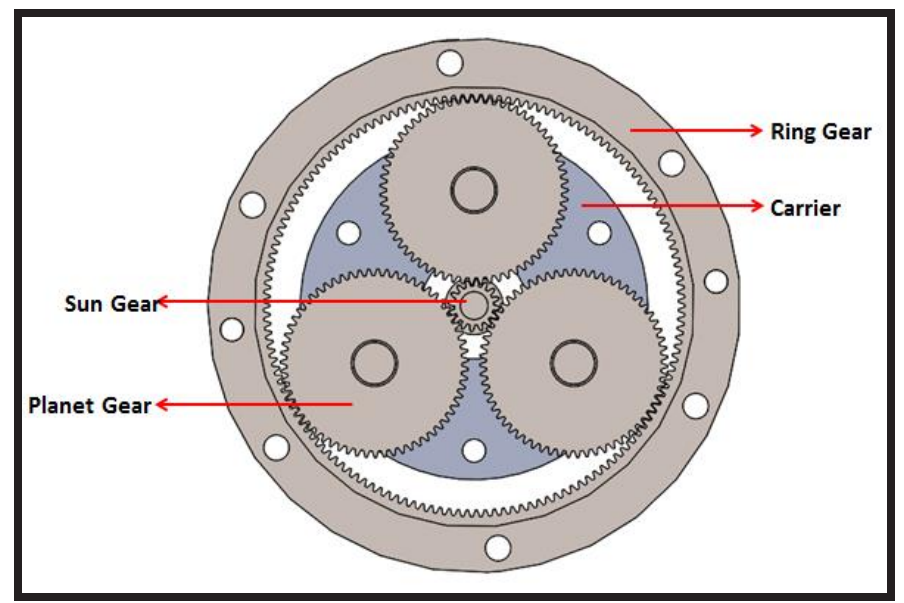

Fig. 3. Schematic of planetary gear drive

Using table 2, number of teeth on sun, planet and ring gear is calculated. From 1st row, it is observed that when a sun gear rotates in clockwise direction, the planet and ring gear rotates in an anti-clock wise direction. Similarly, in third row, if the planet carrier rotates at $\mathrm{y} \mathrm{rpm}$ then sun gear rotates at $\mathrm{x}+\mathrm{y} \mathrm{rpm}$. The planetary gear has three planets revolving and rotating around sun gear. The sun gear and the planet gear are enclosed by ring gear. Three planet gears are coupled to output shaft through a carrier. The planetary gear assembly is shown in Fig. 3.

When ring gear is fixed, the eqn. 3 , is equated to zero

$$
\begin{aligned}
& y-\left(Z_{s} / Z_{i}\right) x=0 \\
& Z_{i}=Z_{s}+Z_{p}
\end{aligned}
$$

By considering, minimum number of teeth on sun gear as 16 teeth, and by using eqn. 4 , the number of teeth on ring gear is calculated to be 143 , and number of teeth on planet is found to be 63 . The module of the planetary gearbox is found by using eqn. 5 .

$$
m=\left(2 * M_{t} / 4 * \sigma * \pi^{2} *_{z} * y\right)^{1 / 3}
$$

By substituting the above data in eqn. 5, module is found to be $1.25 \mathrm{~mm}$. Torque at sun gear is, found by using eqn. 6

$$
P=2 \pi N T_{s} / 60
$$

The power provided at sun gear is considered to be $5 \mathrm{~kW}$. By substituting the value of power in eqn. 6 , we get torque at sun gear as $32,030 \mathrm{~N}-\mathrm{mm}$.

From energy eqn. 7, 8 and 9, torque at ring and carrier is calculated

$$
\begin{aligned}
& T_{S} N_{S}+T_{C} N_{C}+T_{R} N_{R}=0 \\
& T_{S} N_{S}+T_{C} N_{C}=0
\end{aligned}
$$




$$
T_{S}+T_{C}+T_{R}=0
$$

Since the ring gear is fixed, there will be no motion and hence the speed at ring gear is equal to zero. By substituting these values in eqn. 7, 8 and 9, the torque on carrier are calculated to be $-318,300 \mathrm{~N}$-mm, the negative indicates that it is a resisting torque developed by the carrier. On similar calculation, the torque on the ring gear is found to be 286,270 N-mm.

\subsection{Effect of auxiliary motor on generator speed}

In this section a generalized equation is proposed to study the effect of auxiliary motor on the generator speed is carried out. When the generator speed varies from the required speed, the difference in the speed is compensated by using an auxiliary motor. The auxiliary motor in turns drives the gearbox, which is in mesh with ring gear of planetary gearbox. Therefore, to find out the effect of auxiliary motor on the generator speed, the carrier of the planetary gearbox is fixed. And input speed is given to auxiliary motor.

Ring gear speed $=$ Auxiliary motor speed / Auxiliary helical gear ratio* spur gear ratio (10)

Output generator speed $=$ Ring gear speed $*$ gear ratio Ring - Sun

The generalized equation for speed compensation by the auxiliary motor to maintain the constant speed are given by eqn. 10 and 11 .

\section{Modeling and Multi Body Dynamic Simulations}

The arrived dimension of the planetary gearbox and auxiliary gearbox is modeled in modeling software. The modeled system is imported into a multibody dynamics ADAMS software to verify the analytical calculation through kinematic analysis. In addition to this the dynamic analysis is carried out to evaluate the torque and speed required by the auxiliary motor to maintain constant generator speed.

\subsection{Multi body dynamic simulations of planetary gearbox system}

The model is applied with an input speed of $150 \mathrm{rpm}(15.70 \mathrm{rad} / \mathrm{s})$ at carrier of the planetary gearbox as shown in Fig. 4 and simulated for 1 second with 5000 steps. This simulation is carried out for validating the transmission ratio obtained through analytical calculation. Therefore the ring gear is fixed which indicates that the auxiliary motor is in off condition. 


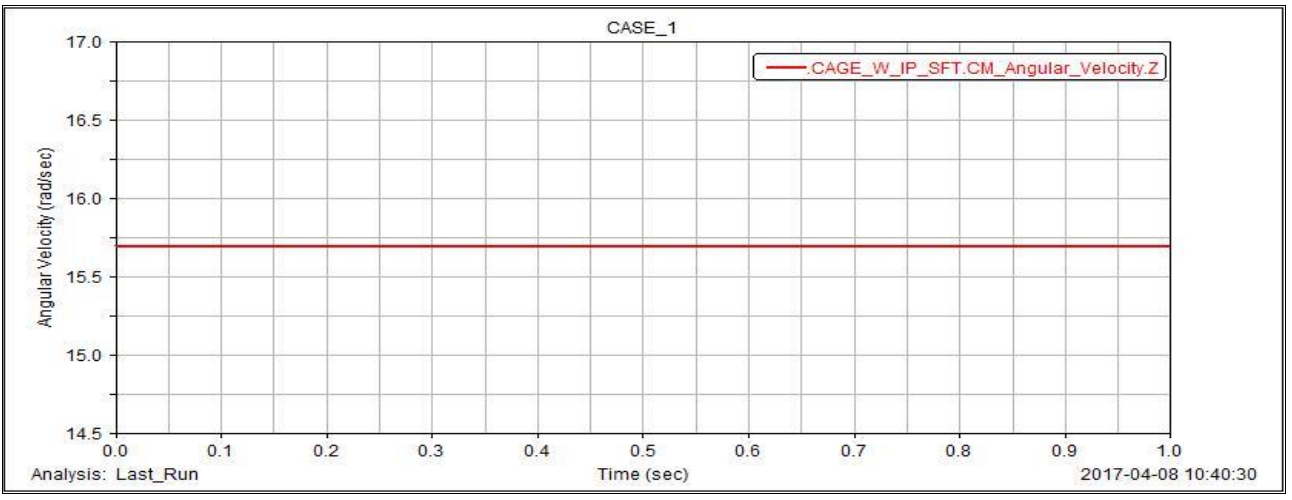

Fig. 4. Speed characteristic of the carrier of planetary gearbox system

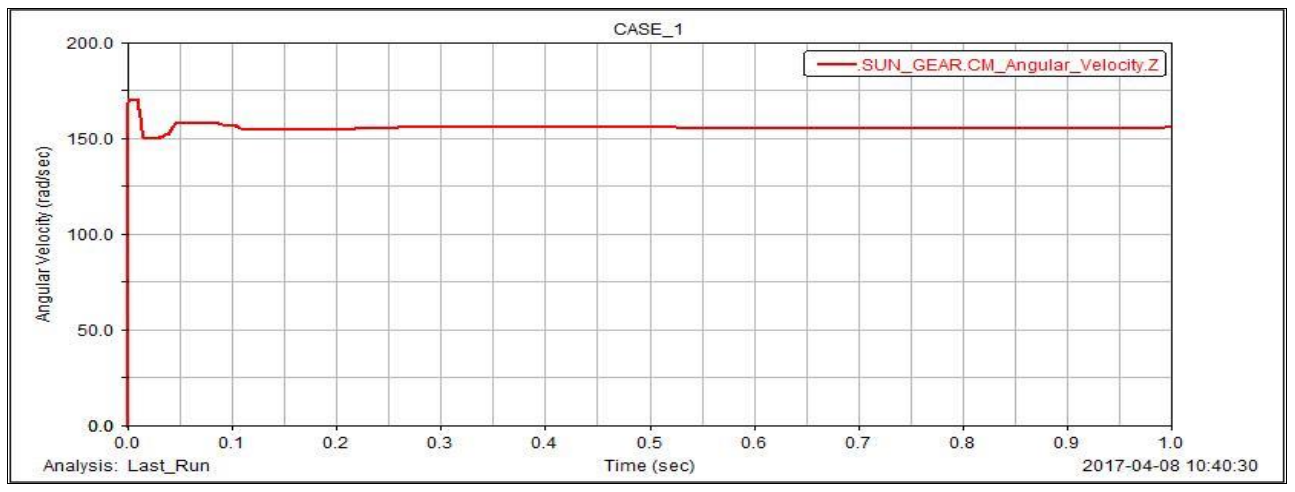

Fig. 5. Speed characteristic of the sun gear of planetary gearbox system

The output is extracted at sun gear and is presented in Fig. 5. From the output plot it can be observed that the sun gear is rotating at $1490 \mathrm{rpm}(156.30 \mathrm{rad} / \mathrm{s})$. When input and output speed ratio is calculated from simulation, it is found to be approximately 1:9.9.

The modeled planetary gearbox is simulated for dynamic condition for analyzing torque requirement. In the dynamic simulation, the input torque of $32,030 \mathrm{~N}-\mathrm{mm}$ is applied at sun gear as per analytical calculation and simulated for 1 second with 5000 steps as shown in Fig. 6. The torque on carrier is measured and is found to be $318,000 \mathrm{~N}-\mathrm{mm}$ and torque variation is shown in Fig. 7. Similarly, the torque variation of ring gear is shown in Fig. 8 and is found to be $285,000 \mathrm{~N}-\mathrm{mm}$.

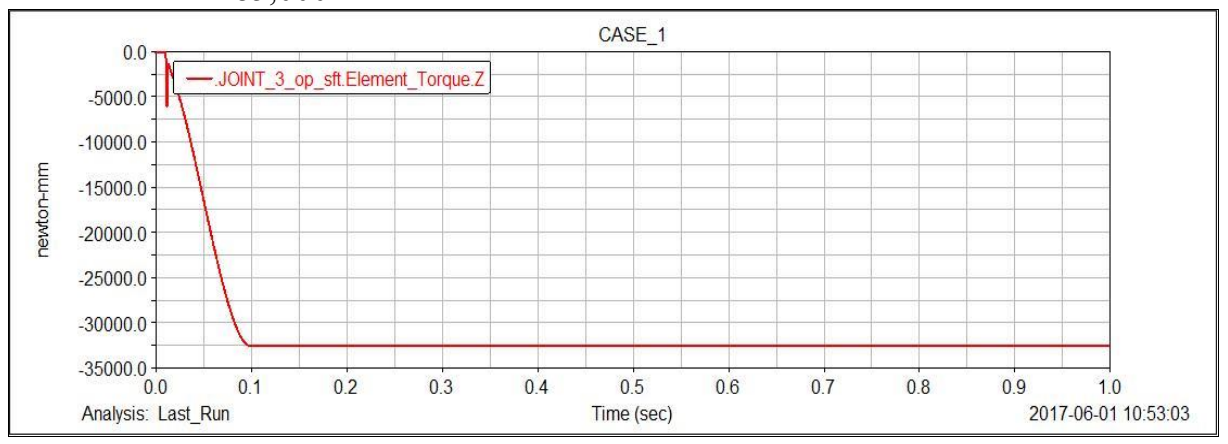

Fig. 6. Torque characteristic of the sun gear of planetary gearbox system 


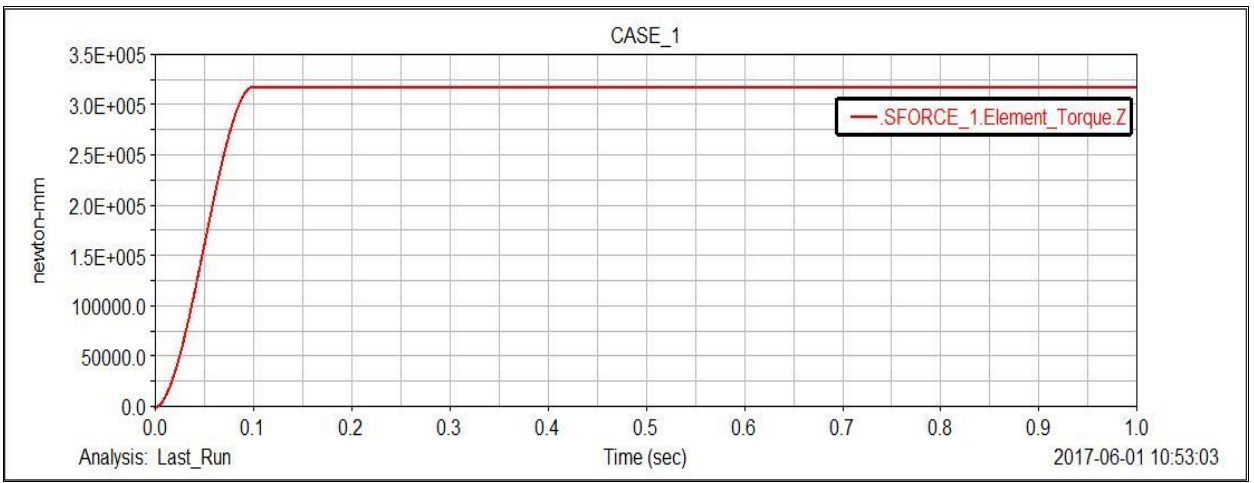

Fig. 7. Torque characteristic of the carrier

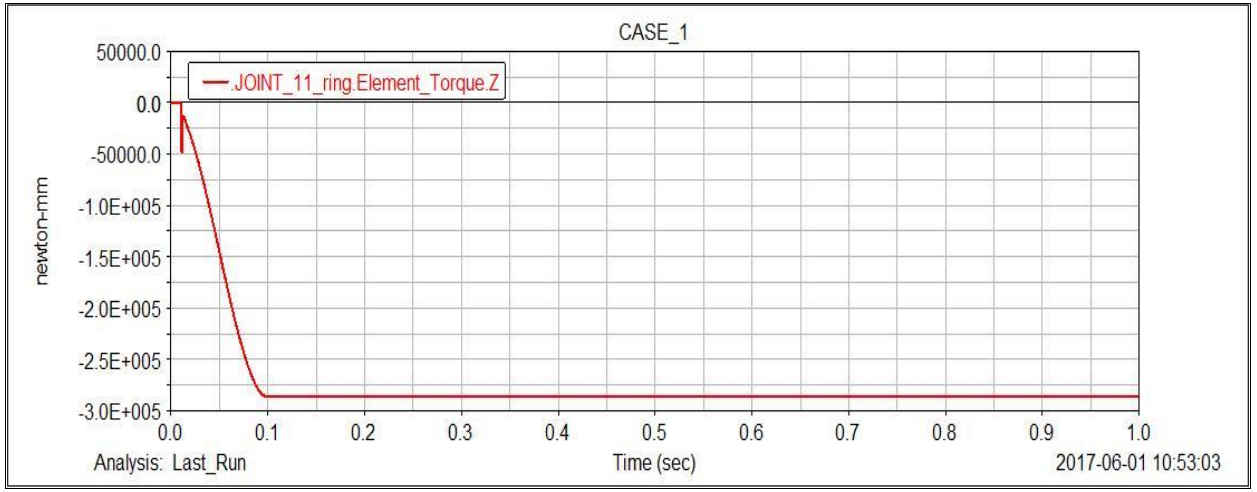

Fig. 8. Torque characteristic of the ring gear of planetary gearbox system

\subsection{Simulation of conceptual design to determine the effect of auxiliary motor speed on generator speed}

The aim of auxiliary motor and gearbox is to maintain constant speed of the generator. To find the effect of auxiliary motor on the sun gear coupled with generator, the simulation is carried out by fixing the carrier of the planetary gearbox. The input speed of 150rpm (15.70 $\mathrm{rad} / \mathrm{s}$ ) is provided to auxiliary motor and corresponding output speed is measured at sun gear which is coupled with generator. Fig. 9 shows the input auxiliary motor speed of 15.70 $\mathrm{rad} / \mathrm{s}(150 \mathrm{rpm})$. From simulation results, the speed of ring gear is measured and found to be $0.866 \mathrm{rad} / \mathrm{s}(8.26 \mathrm{rpm})$ which is shown in Fig. 10. The variation in the speed is due to start up condition and can be neglected.

When the auxiliary motor is rotating at $15.70 \mathrm{rad} / \mathrm{s}(150 \mathrm{rpm})$, the speed at sun gear coupled with generator is measured to be $7.73 \mathrm{rad} / \mathrm{s}(73.89 \mathrm{rpm})$ and is shown in Fig. 11. From the figure it can be observed that the speed of sun gear is not uniform, hence average speed is considered. Therefore the speed reduction ratio from auxiliary motor to sun gear coupled with generator is 2.03 time. 


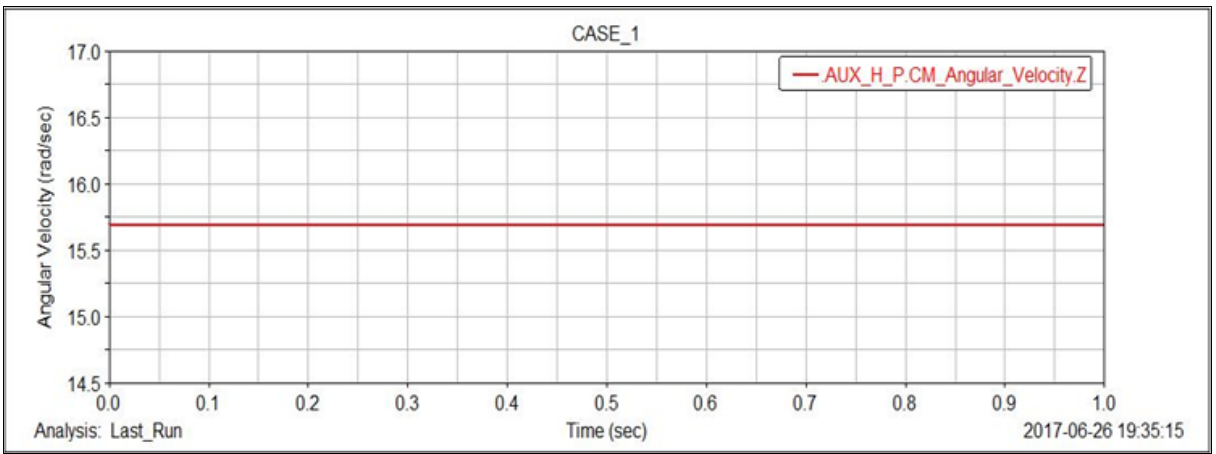

Fig. 9. Auxiliary motor speed

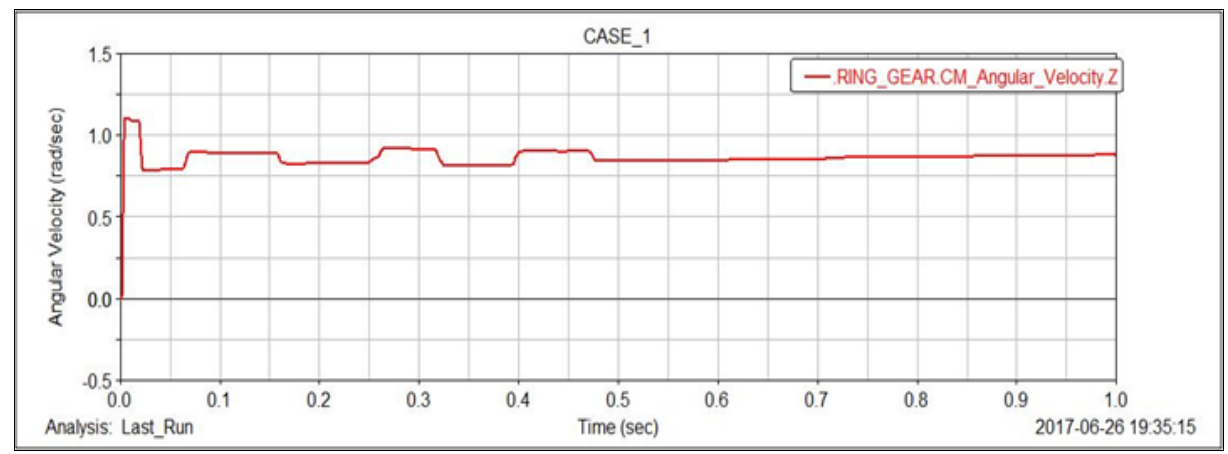

Fig. 10. Speed characteristic of the ring gear of planetary gearbox system

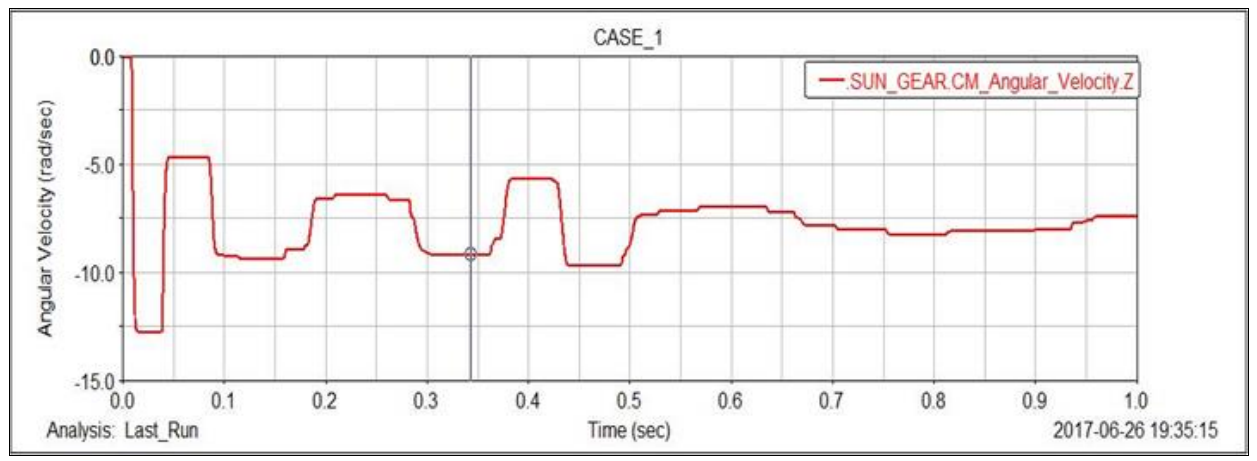

Fig. 11. Speed characteristic of sun gear of planetary gearbox system

\section{Results and discussion}

The table 3, shows the comparison between simulation and analytical result. When auxiliary motor is at off condition, the ring gear rpm is zero indicating that it is fixed and generator speed is $1490 \mathrm{rpm}$. Hence it can be observed that the planetary gearbox is designed for a gear ratio of 1: 9.9. The error between the simulation and analytical result is found to be well within $1 \%$. 
Table 3. Comparison of kinematic analysis result of designed planetary gear system

\begin{tabular}{|l|l|l|l|l|l|}
\hline Particulars & $\begin{array}{c}\text { Turbine } \\
\text { motor } \\
\text { (rpm) }\end{array}$ & $\begin{array}{c}\text { Auxiliary } \\
\text { motor } \\
\text { (rpm) }\end{array}$ & $\begin{array}{c}\text { Carrier } \\
\text { (rpm) }\end{array}$ & $\begin{array}{c}\text { Generator } \\
\text { Sun } \\
\text { gear } \\
\text { (rpm) }\end{array}$ & $\begin{array}{c}\text { Ring } \\
\text { gear } \\
\text { (rpm) }\end{array}$ \\
\hline $\begin{array}{l}\text { Simulation } \\
\text { Result }\end{array}$ & 150 & - & 150 & 1489.72 & 0 \\
\hline $\begin{array}{l}\text { Analytical } \\
\text { Result }\end{array}$ & 150 & - & 150 & 1490.62 & 0 \\
\hline
\end{tabular}

The table 4, shows results of torque comparison of planetary gearbox when the auxiliary gearbox is under off condition. The error between the simulation and analytical result is found to be well within $1 \%$.

Table 4. Comparison of torque characteristics

\begin{tabular}{|c|l|l|c|c|c|}
\hline Particulars & $\begin{array}{c}\text { Turbine } \\
\text { motor } \\
(\mathbf{r p m})\end{array}$ & $\begin{array}{c}\text { Auxiliary } \\
\text { motor } \\
\mathbf{( r p m})\end{array}$ & $\begin{array}{c}\text { Carrier } \\
\mathbf{( N -} \\
\mathbf{m m})\end{array}$ & $\begin{array}{c}\text { Sun } \\
\text { gear } \\
\mathbf{( N -} \\
\mathbf{m m}\end{array}$ & $\begin{array}{c}\text { Ring } \\
\text { gear } \\
(\mathbf{N}-\mathbf{m m})\end{array}$ \\
\hline Simulation Result & 150 & - & 310670 & 32030 & 278650 \\
\hline Analytical Result & 150 & - & 318300 & 32030 & 286270 \\
\hline
\end{tabular}

The table 5, shows the comparison of simulation and analytical results when the auxiliary motor is running at $150 \mathrm{rpm}$. Analytical results are calculated using the eqn. 10 and 11 . The error between the simulation and analytical result is found to be well within $1 \%$.

Table 5. Kinematic analysis results of Effect of Auxiliary motor speed on generator speed

\begin{tabular}{|l|l|l|l|l|l|}
\hline \multirow{2}{*}{ Particulars } & $\begin{array}{c}\text { Turbine } \\
\text { motor }\end{array}$ & $\begin{array}{c}\text { Auxiliary } \\
\text { motor }\end{array}$ & Carrier & $\begin{array}{c}\text { Sun } \\
\text { gear }\end{array}$ & $\begin{array}{c}\text { Ring } \\
\text { gear }\end{array}$ \\
\cline { 2 - 6 } & \multicolumn{5}{|c|}{ Speed in rpm } \\
\hline Simulation Result & - & 150 & 0 & 73.89 & 8.26 \\
\hline Analytical Result & - & 150 & 0 & 74.09 & 8.29 \\
\hline
\end{tabular}

\section{Conclusions}

Conceptual design of planetary gearbox system is developed for maintaining constant generator speed for variable input turbine speed. The planetary gearbox is designed for 1:9.9 speed ratio. Speed ratio between the auxiliary motor and sun gear coupled with generator is found to be 2.03:1. The analytical and simulation result are within the acceptable limits. Hence the conceptual design can be used to in micro hydro power plant for power generation.

\section{References}

1. Doolla and T.S. Bhatti, J. Electr. Pow. Syst. Res. 76, 889-896, (2006)

2. A. M. A. Haidar, Md. F. M. Senan, A. Noman and T. Radman, J. Renew. Sust. Energ. Rev., 16, 518-524, (2012) 
3. B. A. Nasir, Energ. Proc., 50, 19-29, (2014)

4. J. A. Laghari, H. Mokhlis, A. H. A. Bakar and H. Mohammad, J. Renew. Sust. Energ. Rev., 20, 279-293, (2013)

5. C. Jaliu, D. Diaconescu and R.Saulescu, , Renew. Energ. Pow. Qual. J, 1, 650-653, (2008)

6. R. Saulescu, C. Jaliu, D.V. Diaconescu and O. Climescu, Proc. of ASME 2011 Int. Des. Eng. Tech. Conf. and Comp. Info. Eng. Conf., 1-10, (2011)

7. G. M. Maitra, Handbook of Gear Design, Tata McGraw-Hill Pub. Comp. Ltd., (2001) 